\title{
A ecologia por sequência didática: alternativa para o ensino de biologia
}

\author{
Ecology by didactic sequence: \\ alternative to teaching biology
}

\section{La ecología por secuencia didáctica:} alternativa para la enseñanza de biología

ELGA CRISTINA TORRES PEREIRA*

Universidade do Estado do Amazonas, Manaus- AM, Brasil.

\section{HILÉIA MONTEIRO MACIEL-CABRAL ${ }^{* *}$}

Universidade do Estado do Amazonas, Manaus- AM, Brasil

CIRLANDE CABRAL DA SILVA***

Instituto Federal de Educação, Ciência e Tecnologia do Amazonas, Manaus- AM, Brasil

\section{LUIZ CALDEIRA BRANT DE TOLENTINO-NETO}

Universidade Federal de Santa Maria, Santa Maria- RS, Brasil.

\section{PATRICIA MACEDO DE CASTRO}

Universidade Estadual de Roraima, Boa Vista- RR, Brasil.

* Graduada em Licenciatura em Ciências Biológicas pela Universidade do Estado do Amazonas. Atualmente é aluna de mestrado do Programa de Pós-Graduação em Entomologia do Instituto Nacional de Pesquisas da Amazônia. E-mail: <elgacristinatp@gmail.com>.

* Doutoranda no Programa de Pós-Graduação em Educação em Ciências e Matemática da Rede Amazônica de Educação em Ciências e Matemática, e mestre em Educação em Ciências na Amazônia pela Universidade do Estado do Amazonas. Atualmente é professora Assistente da Universidade do Estado do Amazonas. E-mail: <hileiamaciel@gmail.com>.

** Possui doutorado em Ensino de Ciências pela Universidade Federal do Mato Grosso. É professor do Instituto Federal de Educação, Ciência e Tecnologia do Amazonas e é professor permanente do Mestrado Profissional em Educação Profissional e Tecnológica (profEPT). Atualmente realiza pós-doutorado em Educação em Ciências pela Universidade Federal de Santa Maria. E-mail: <cirlandecabral@gmail.com>.

**** Doutor em Educação pela Universidade de São Paulo, é professor do Departamento de Metodologia do Ensino do Centro de Educação da Universidade Federal de Santa Maria. É líder do Grupo Interinstitucional Desempenho Escolar e Inclusão Acadêmica (IDEIA). E-mail: <lcaldeira@smail.ufsm.br>.

***** É doutora em Ciências Biológicas (Zoologia) pela Universidade de São Paulo. Atua como professora do Curso de Licenciatura em Ciências Biológicas e do Programa de Pós-Graduação Mestrado Profissional em Ensino de Ciências da Universidade Estadual de Roraima. Pesquisadora do Museu Integrado de Roraima/IACTI-RR, Boa Vista- RR, Brasil e do Instituto de Amparo à Ciência, Tecnologia e Inovação do Estado de Roraima. E-mail: <patriciacastro@uerr.edu.br>. 
RESUMO: Este trabalho utilizou uma sequência didática para ensinar ecologia aos alunos do $3^{0}$ ano do ensino médio em uma escola da rede pública da cidade de Manaus-AM. Tem como objetivo promover a aprendizagem dos alunos a respeito dos conteúdos em ecologia por meio de uma sequência didática com atividades variadas. A pesquisa demonstrou que a utilização de meios alternativos facilita o processo de aprendizagem. Alguns fatores interferiram no desenvolvimento dessa atividade, como o número reduzido de alunos e alunos focados na realização de outras atividades. Mesmo assim, acredita-se que ocorreu aprendizagem por parte deles. Portanto, deve-se buscar sempre alternativas diferenciadas para facilitar cada vez mais o processo ensino aprendizagem.

Palavras-chave: Ensino médio. Ensino de biologia. Ecologia. Sequência didática.

ABSTRACT: This work used a didactic sequence to teach ecology to the students of the 3 rd year of high school in a public school in Manaus - AM. It aims to promote students' learning of contents in ecology through a didactic sequence with varied activities. The research showed that using alternative means facilitates the learning process. Some factors interfered with the development of this activity, such as the reduced number of students and students focused on performing other activities. All the same, it is believed that learning has occurred on their part. Therefore, one should always seek differentiated alternatives to increasingly facilitate the teaching-learning process.

Keywords: High School. Biology teaching. Ecology. Didactic Sequence.

RESUMEN: Este trabajo utilizó una secuencia didáctica para enseñar ecología a los estudiantes del tercer año de secundaria en una escuela pública en Manaus-AM. Su objetivo es promover el aprendizaje de los estudiantes sobre los contenidos de ecologia a través de una secuencia didáctica con actividades variadas. La investigación há demostrado que el uso de medios alternativos facilita el proceso de aprendizaje. Algunos factores interfirieron con el desarrollo de esta actividad, como el número reducido de estudiantes y estudiantes enfocados en realizar otras actividades. Aun así, se piensa que el aprendizaje se produjo. Por lo tanto, uno siempre debe buscar alternativas diferenciadas para facilitar cada vez más el proceso de enseñanza-aprendizaje. 
Palabras clave: Enseñanza secundaria. Enseñanza de biología. Ecología. Secuencia didáctica.

\section{Introdução}

educação no Brasil mudou bastante nos últimos anos, mas ainda está longe
de ser satisfatória (BROCK; SCHWARTZMAN, 2005). Até não muito tempo,
os problemas de educação no nosso país eram outros e estavam relacionados principalmente à falta de escolas, evasão escolar de muitas crianças em idade precoce e à carência de verbas governamentais para a educação (KLEIN; RIBEIRO, 1991). Apesar de atualmente, em alguns estados ou regiões estes problemas não terem sido completamente resolvidos, temos que considerar que diminuíram bastante, constituindo-se agora os problemas relacionados à educação e às questões didáticas, ou seja, a necessidade de desenvolver, cada vez mais, maneiras de fazer os alunos aprenderem significativamente (MOREIRA, 2011). Esse processo significativo de ensino-aprendizagem, para ocorrer, deve levar em consideração tanto o professor quanto o aluno, sendo necessários suportes para os docentes aperfeiçoarem as suas aulas visando uma efetiva aquisição de conhecimentos pelos educandos.

Diversas são as estratégias que o professor pode utilizar em sala de aula para facilitar o ensino e uma delas é, sem dúvida nenhuma, a sequência didática. Esta é uma unidade de análise que permite a avaliação sob uma perspectiva processual, incluindo as fases de planejamento, aplicação e avaliação (ZABALA, 1998). É uma das estratégias importantes para o processo de ensino-aprendizagem, sendo esta, ainda, um instrumento fundamental para o professor na abordagem de conceitos de difícil compreensão. Determinados conceitos, quando apresentados por meio de uma sequência didática bem elaborada, são assimilados mais facilmente e com isso os alunos obtêm um aprendizado significativo, pois esta estratégia torna o conteúdo mais atrativo e de fácil compreensão, despertando a curiosidade, a motivação do aluno e deixando a aula mais interativa.

Para Kobashigawa et al. (2008), a sequência didática é um conjunto de atividades, estratégias e intervenções planejadas etapa por etapa pelo docente para que o entendimento do conteúdo ou tema proposto seja alcançado pelos discentes. Lembra um plano de aula, entretanto, é mais amplo que este por abordar várias estratégias de ensino e aprendizagem e por ser uma sequência de vários dias.

Por meio da sequência didática, o docente que tenha fragilidade em algum conhecimento pode ter a oportunidade de adquiri-lo enquanto se prepara para lecionar tal tema. Em todo momento, o docente pode intervir para a melhoria no processo ensino e aprendizagem, oportunizando situações para que o educando assuma uma postura reflexiva e se torne sujeito do processo (LIMA, 2018). 
Muitos são os temas biológicos em que os alunos sentem grandes dificuldades e um deles é, sem dúvida nenhuma, o estudo da ecologia.

Como os estudos de ecologia estão diretamente ligados às questões de funcionamento do ecossistema, é de extrema importância que as crianças e os jovens aprendam nas escolas seus princípios básicos e fundamentações teóricas para que esse tema transversal seja trabalhado de maneira correta. Para Jacobi (2003), a escola como educadora tem um papel fundamental de conscientização dos futuros cidadãos.

A ecologia, por tratar-se do estudo das relações entre os seres vivos e destes com o meio em que vivem, apresenta-se como um componente curricular interdisciplinar do ensino de biologia, pois seu estudo se dá em diversos níveis hierárquicos, e, diversas vezes, para resolver os seus problemas conceituais e práticos, são necessários vários conteúdos de biologia, como um pré-requisito para a compreensão desses estudos (LINHARES; GEWADSZNAJDER, 2008).

Deste modo, o professor precisa utilizar metodologias alternativas para ensinar o conteúdo, pois envolve um grupo de conceitos interligados que se comunicam com outras áreas da biologia. Devido a isso são necessárias estratégias que proporcionem a assimilação de seus conceitos básicos. Morin (2015) explica a interligação de todos os conhecimentos, combate o reducionismo instalado em nossa sociedade e valoriza o complexo.

Sendo verificada, então, a necessidade de se trabalhar de forma diferenciada conteúdos de ecologia com os alunos de uma turma de $3^{\underline{0}}$ ano do ensino médio de uma escola pública estadual de Manaus-AM, durante a disciplina de Estágio Supervisionado IV da Universidade do Estado do Amazonas (UEA), foram trabalhados os conceitos básicos em ecologia e ecossistemas (teias e cadeias alimentares e o fluxo de energia nos níveis tróficos) por meio de sequência didática, em três aulas, utilizando diversos recursos.

Deste modo, o trabalho teve como objetivo principal promover a aprendizagem dos alunos a respeito dos conteúdos em ecologia, por meio de uma sequência didática com atividades variadas.

\section{O campo da pesquisa}

O presente trabalho foi realizado durante o Estágio Supervisionado IV, onde os conteúdos de ecologia foram ministrados por meio de uma sequência didática para uma turma de $3^{\circ}$ ano do ensino médio, da Escola Estadual Prof. - Ondina de Paula Ribeiro, localizada no bairro Japiim I, em Manaus-AM.

O Estágio Supervisionado IV é a última disciplina de estágio curricular do Curso de Licenciatura em Ciências Biológicas da Universidade do Estado do Amazonas (UEA), ofertada no $8^{o}$ período do curso e tem ênfase na prática de ensino de biologia, sendo 
assim realizada com alunos de $1^{\circ}$ ao $3^{\circ}$ ano do ensino médio. Essa disciplina possui dois momentos, o de etapas de observações (EO) e o de etapas de regências (ER).

O EO é a etapa inicial em que o estagiário faz o diagnóstico da escola, observando-a em diversos aspectos (estrutural, a comunidade na qual está inserida, a forma como o professor conduz as aulas, e outros). Já o ER é a etapa em que o estagiário ministra aulas e realiza atividades de modo que venha a sanar, quando possível, deficiências diagnosticadas no ensino da disciplina.

O estágio supervisionado tem o objetivo de fazer com que o graduando, agora estagiário, obtenha experiências, vivenciando a realidade do ambiente educativo de escolas públicas, a fim de conhecer as características do ambiente escolar, acompanhar o desenvolvimento das atividades do professor-campo na escola, colaborar com o professor nas necessidades mais urgentes do processo de ensino aprendizagem, participar juntamente com o professor das atividades do trabalho e, principalmente como estagiário, registrar todas as situações vivenciadas durante o período de estágio.

Acredita-se que o estágio supervisionado curricular é um espaço de construção de múltiplos significos no processo de formação de professores e deve ser entendido como uma oportunidade de formação contínua da prática pedagógica.

Segundo Uchoa (2015) não basta apenas o aluno estagiário realizar práticas no estágio supervisionado, também são necessários momentos de reflexões dos diagnósticos e das vivências experimentadas durante o período do estágio. De acordo com Pereira e Baptista (2009), é imprescindível a realização de uma reflexão dos dilemas encontrados na prática pedagógica em sala de aula vivenciada pelos licenciandos, visando a superação dos obstáculos como uma forma de adquirir competências e habilidades para lidar com as diversas situações que possam surgir no decorrer da carreira. Segundo os autores, a partir dessa reflexão, os futuros professores serão capazes de avaliar a sua própria prática, diagnosticar suas principais limitações e encontrar soluções para resolver problemas

\section{Caracterizando a escola}

A E. E. Prof. ${ }^{\text {a }}$ Ondina de Paula Ribeiro possui 12 salas de aula amplas, com carteiras bem conservadas (todas as salas funcionam pela manhã e somente oito no turno vespertino), uma quadra poliesportiva, sala de informática, laboratório de ciências e biblioteca. A escola atualmente possui 41 professores, sendo dois de biologia no período da tarde e 878 alunos matriculados nos dois horários, sendo em média, 40 a quantidade de alunos por turma.

De modo geral, é uma escola em que quase não há pichações nas paredes, no entanto, sofre com a poluição causada por fezes de pombos. A escola dispõe de apenas um bebedouro e a área de lanche é pequena para a quantidade de alunos e, apesar de ser menor 
no turno vespertino (no qual o estágio foi realizado), é insuficiente, deixando-os agitados. Foi verificada, ainda, uma constante alternância dos alunos presentes em determinadas aulas, ou seja, de 40 alunos (média das turmas), somente 20 alunos, em média, estavam presentes nas aulas, pois hora faltavam uns e hora faltavam outros.

\section{Realidade da escola - professora de biologia/alunos}

Essa pesquisa ocorreu durante o desenvolvimento do Estágio Supervisionado IV, quando, no turno vespertino, acompanhou-se a professora de biologia, que é responsável por oito turmas, sendo três de $1^{\circ}$ ano, três de $2^{\underline{0}}$ ano e duas de $3^{\circ}$ ano.

Nos cinco dias de observações, registrou-se que a professora trabalhou com o livro didático, quadro branco e pincel para explicar sobre os conteúdos de biologia.

As disciplinas de ciências e biologia envolvem uma série de conceitos E é importante que alguns desses fundamentos sejam bem compreendidos. Para tornar o processo de compreensão dos conceitos de ciências e biologia mais efetivos e dinâmicos, deve-se utilizar ferramentas que facilitem o aprendizado. Uma das ferramentas é procurar passar o conhecimento por meio de alguma estratégia em que o aluno sinta prazer.

A utilização de aulas mais atrativas no ensino de biologia e de ciências é praticamente inquestionável e, em geral, os professores das redes públicas parecem compartilhar essa ideia (MOREIRA, 2003). Concorda-se com Nicola e Paniz (2016), quando afirmam que, com o passar do tempo, o aluno perde o interesse pelas aulas de ciências/biologia, pois muito pouco de diferente é feito para tornar a aula mais atrativa e que o motive a aprender e construir seu próprio conhecimento. Os recursos utilizados geralmente são quadro e giz e, assim, a aula acaba virando rotina, não chamando a atenção dos alunos para os conteúdos abordados.

Silva, Maciel e Nery (2017) afirmam que a não utilização de diferentes recursos didáticos pode ocorrrer por vários motivos, sendo os principais o desinteresse dos alunos e o pouco tempo de aula que o professor tem com cada turma.

Em função dessa realidade, partimos da perspectiva de envolver e levar uma nova interação para esses alunos no estudo de ecologia, em que eles participassem de maneira mais dinâmica, se envolvendo no processo de aprendizagem e contribuindo para esse processo, objetivando não apenas a participação, mas a compreensão do conteúdo, para que ocorresse uma aprendizagem mais eficaz. Concorda-se com Lima (2018), quando afirma que a aprendizagem é, antes de tudo, mudança de comportamento em relação ao que foi apreendido. É um estágio de vida que se modifica por toda a existência do indivíduo, pois é através dela que o professor, sujeito indispensável deste processo, aparece como o principal mediador do ensino aprendizagem. 
Essa forma diferenciada no processo ensino-aprendizagem foi realizada por meio de sequência didática de conteúdos em ecologia, uma vez que é conhecida a dificuldade que os professores de $3^{0}$ ano do ensino médio têm em trabalhar esse assunto. A ecologia é um estudo bastante complexo e abrangente e é por meio dela que os alunos podem entender os impactos ambientais e os desequilíbrios causados às populações de todos os seres vivos, em decorrência da ação humana (SILVA, 2012).

Segundo Lima (2018), por meio da sequência didática, o docente que tenha fragilidade em algum conhecimento pode ter a oportunidade de adquiri-lo, enquanto se prepara para lecionar tal tema. A sequência didática vem como uma sugestão da ação pedagógica.

No entender de Fernandes (1998), a maioria dos alunos vê a biologia apresentada em sala como uma disciplina cheia de nomes, ciclos e tabelas a serem decorados, enfim, uma disciplina "chata" e inútil. De acordo, com Barbosa (2004), o mesmo é percebido para os conteúdos de ecologia. Este autor diz que apesar do dinamismo embutido nos diferentes tópicos abordados pela ecologia, eles são, na maioria das vezes, transmitidos de formas sem graça e enfadonha, em que o aluno é transformado, quase sempre, num elemento passivo no processo de aprendizagem.

Diante disso, pode-se perceber que é essencial ao ensino de biologia, no que diz respeito ao ensino de ecologia, a utilização de metodologia que priorize o desenvolvimento da capacidade lógica e de questionamento do aluno, pois o aprendizado se desenvolve através da dúvida, do questionamento e de trabalhos individuais e coletivos dos que estão envolvidos com ela (ANDRADE, 2005).

\section{Desenvolvendo a pesquisa}

A sequência didática da pesquisa foi realizada em três aulas ou etapas, para as quais foram elaborados planos de aula com os objetivos a serem alcançados: $a) 1^{\underline{a}}$ aula: Conceitos básicos em ecologia; b) $2^{\underline{a}}$ aula: Teias e cadeias alimentares/fluxo de energia nos níveis tróficos; c) 3aa aula: Atividade prática.

$1^{a}$ aula: Essa aula foi ministrada, utilizando como recurso somente o quadro branco, roteiro de aula e um cartaz, que foi afixado na parede para ser utilizado para a explicação dos conceitos básicos de ecologia e níveis de organização biológica. Após a explicação, a estagiária realizou uma dinâmica de grupo para que compreendessem os níveis de organização ecológica. Nessa dinâmica, escrevemos em uma folha de papel os nomes de todos os níveis de organização biológica (átomos, moléculas, organelas, células, tecidos, órgãos, sistemas, organismos, população, comunidade ecossistema e biosfera) e o distribuímos para os alunos, onde cada um deles iria "representar" um nível de organização. Em seguida solicitou-se que eles formassem "agrupamentos" apenas com os 
níveis ecológicos (organismo, população, comunidade, ecossistema e biosfera). Após essa dinâmica aplicou-se uma atividade individual, composta de cinco questões, sendo três objetivas e duas subjetivas, a fim de verificar o conhecimento adiquirido sobre a temática proposta. O objetivo desta aula foi verificar como os alunos haviam entendido os fundamentos básicos dos conceitos de ecologia e justificar a importância dos estudos ecológicos para o bem-estar atual e futuro da humanidade. Além disso, procurou-se compreender como os alunos interrelacionavam os conceitos de organismo, população, comunidade, ecossistema e biosfera, levando em consideração que o funcionamento de um ecossistema resulta da interação entre seus componentes bióticos e abióticos.

$2^{\underline{a}}$ aula: Esta aula foi ministrada, utilizando como recurso uma seleção de slides para explicação do conteúdo sobre teias e cadeias alimentares/fluxo de energia nos níveis tróficos. Após a explicação do conteúdo, os alunos se organizaram em trio, para resolver, conjuntamente, uma atividade composta de questões objetivas sobre o assunto abordado. A aula teve como objetivo compreender as relações entre produtores, consumidores e decompositores, em cadeias e teias alimentares e o fluxo de energia nos níveis tróficos, além de identificar os níveis tróficos de um ecossistema, interpretar teias alimentares e pirâmides ecológicas.

3a aula: Depois das duas aulas a respeito dos conceitos básicos em ecologia e a explicação a respeito das teias e cadeias alimentares e o fluxo da energia nos níveis tróficos, os alunos desenharam uma teia alimentar e uma pirâmide ecológica, de modo que inter-relacionassem os dois conceitos. Para realizar a atividade, a turma foi dividida em duas equipes, sendo que cada uma recebeu uma questão retirada de um livro didático que correspondia aos dois conteúdos, servindo, então, como roteiro para a atividade proposta. Além disso, as equipes receberam todo o material necessário para a execução da atividade, como tesouras, cola, emborrachado, figuras, régua etc.

Ao final dessa atividade, elaborou-se um conjunto de perguntas sobre o tema estudado para verificar a compreensão e assimilação dos conteúdos. Bordenave e Pereira (2002) ressaltam a importância das estratégias do professor no emprego de diversas formas de interação para oportunizar aos alunos a construção do conhecimento de acordo com as experiências individuais, subjetivas, dos conhecimentos prévios e da maneira própria de interpretar as informações.

\section{Resultados e discussão}

$1^{\underline{a}}$ aula: Neste primeiro dia de aula, estavam presentes somente 12 alunos, como consequência de já estar próximo o final do ano letivo, uma vez que é comum, com a aproximação do final do ano, a evasão nas salas de aula. Percebeu-se que alguns desses

alunos utilizavam fone de ouvido ou não faziam questão em prestar atenção naquilo 
que estava sendo abordado. Em função disso, apenas quatro alunos entregaram a atividade avaliativa, pois a maioria não quis resolver, mesmo disponibilizando a eles um prazo maior. Observou-se que, quando solicitado para que se levantassem para realizar a dinâmica, eles o fizeram prontamente e interagiram com a turma.

Os alunos foram instigados durante a dinâmica para comentar sobre os níveis de organização ecológica que eles mesmos estavam representando. No diálogo travado entre a estagiária e os alunos verificou-se que eles compreenderam os conceitos de organismo, indivíduo, população, comunidade, ecossistema e biosfera.

Essa dinâmica foi muita válida, pois, o simples fato de se movimentarem pela sala ou ensinar-lhes através de uma dinâmica surtiu um efeito positivo na aprendizagem. Foi notória a mudança na expressão facial e no comportamento geral quando iniciada a atividade. É importante que o professor atente para esses pequenos detalhes, que muitas vezes passam despercebidos durante as aulas.

Silva (2008) diz que o uso da dinâmica de grupo em salas de aula constitui-se em uma possibilidade de exercitar a vivência com ludicidade e em desafio; e que, se esta vivência for trabalhada sobre um plano de ensino estruturado permitirá que os alunos sejam induzidos a reflexões que podem produzir cognição de um dado paradigma, seja ele qual for.

Ao término da dinâmica foi aplicada a atividade avaliativa e, apesar de somente quatro alunos terem participado, 75\% deles obtiveram o conceito "Excelente", mostrando que a explicação e a dinâmica foram suficientes para a compreensão do conteúdo.

$2^{\underline{a}}$ aula: Nessa aula, os 13 alunos estavam mais concentrados e atentos para a explicação; poucas vezes foi necessário chamar a atenção e houve a participação da turma quando feitas as perguntas, sendo que pelo menos dois alunos participaram constantemente durante a aula. Durante a aula foi notado que os alunos criaram expectativas em relação às aulas da estagiária, pois no EO essa turma era barulhenta, os alunos saiam constantemente enquanto a professora explicava o conteúdo.

Acredita-se que são diversos os fatores que contribuem para que a insatisfação se instale, como a formação deficitária do professor, falta de tempo para o estudo, para planejamento e troca de experiências, excesso de alunos em sala de aula, falta de estrutura física e recursos materiais, baixos salários e a falta de compromisso por parte de alguns.

Os resultados obtidos com a atividade proposta na segunda aula foram ótimos, uma vez que os acertos foram categorizados em cinco conceitos, nos quais a maioria $(46,2 \%)$ acertou oito ou sete questões propostas, e com o restante predominaram os conceitos "Excelente" (15,4\%) e "Bom" (30,8\%) .

Em relação à quantidade de alunos que erraram as questões, foi verificada uma maior dificuldade em relação à primeira, segunda, quarta e sexta questão, sendo que na segunda e quarta questão, seis dos 13 alunos não marcaram a alternativa correta, e na primeira e sexta foram oito e cinco dos 13 alunos que não responderam corretamente. 
As questões correspondem à posição que ocupam os seres vivos no ecossistema (produtor, consumidor ou decompositor) e a identificação dos níveis tróficos nas teias alimentares. No entanto, a maioria recebeu conceitos positivos: quando somadas as porcentagens das categorias "Excelente" e "Ótimo" este resultado é bem maior que o das outras categorias juntas (61,6\%).

$3^{\underline{a}}$ aula: Poucos alunos participaram da atividade, a maioria não quis participar (mesmo avisado sobre o prêmio para a equipe que mais se destacasse) porque estavam fazendo uma atividade para o professor de outra disciplina. Desse modo, participaram somente 10 alunos, sendo cinco em cada equipe.

Na equipe 01 (na qual os alunos ficaram responsáveis pela construção de uma teia alimentar), poucos haviam assistido às aulas anteriores, o que dificultou realizarem a atividade, sendo necessária a ajuda da estagiária. Já a equipe 02 (que ficou responsável por elaborar a pirâmide ecológica) conseguiu realizar a atividade sem necessitar de ajuda da estagiária, obtendo um bom desempenho e todos os cinco integrantes haviam assistido às aulas.

Como os alunos da equipe 01, em sua maioria, ainda não haviam tido contato com o conteúdo, as perguntas foram feitas e respondidas pela própria estagiária, enquanto se explicava a eles como os seres vivos são organizados em suas relações de alimentação em um ecossistema. Em seguida foi solicitado que eles identificassem os seres vivos das imagens ali apresentadas, quanto às suas posições na teia alimentar, e que explicassem a organização da teia alimentar que construíram.

Os alunos da equipe 02 tiveram um bom desempenho na execução da atividade e realizaram-na em tempo suficiente. Ao perguntar-lhes qual era o tipo de pirâmide ecológica eles souberam responder que se tratava de uma pirâmide de biomassa e, quando perguntado se em caso de invertê-la, isto é, colocá-la de cabeça para baixo, poderia representar uma pirâmide de energia. Justificaram ainda que a energia nos níveis tróficos é unidirecional e diminui conforme passa por esses níveis, devido parte desta ser perdida para o ambiente.

O período de aplicação dessa atividade não foi o mais adequado, uma vez que se aproximou do término do ano letivo, período em que os alunos, em especial os do $3^{0}$ ano, estão envolvidos com outras atividades (colação de grau, formatura e outros). Mesmo assim, o resultado obtido foi bastante positivo, pois os alunos participantes se dedicaram e pôde ser evidenciada a aprendizagem dos conteúdos ministrados. Notou-se, ainda, que a equipe 01 conseguiu entender o conteúdo, pois souberam identificar os seres produtores, consumidores e decompositores, bem como os níveis que ocupam na teia alimentar.

Este resultado evidencia o posicionamento e "olhar" que o professor deve ter em relação às circunstâncias adversas que atrapalham a execução da aula, e, ainda, a não desanimar quando são poucos os alunos que querem participar de uma atividade diferenciada. Pelo contrário, devem buscar cada vez mais, maneiras de estimulá-los. Concorda-se 
com Moreira, (2014) quando afirma que torna-se relevante conhecer o que os docentes pensam sobre o ensino e as estratégias fundamentais para ensinar com qualidade e compreender como se estabelece a relação entre elas e as estratégias utilizadas pelos alunos no momento do aprendizado.

Por outro lado, Tapia e Fita (2004) dizem que o aluno pode estar motivado ou desmotivado, de acordo com o seu interesse e condições dentro do ambiente escolar e, com isso, a escola deve proporcionar um ambiente de qualidade. Nesse ambiente, o professor deve trabalhar estratégias didáticas diferenciadas.

\section{Considerações finais}

Apesar de todas as dificuldades durante a execução das atividades propostas e que possivelmente interferiram nos resultados da realização das aulas, ainda assim, foram obtidos resultados positivos. As aulas realizadas por meio da sequência didática com a turma de $3^{0}$ ano foram, sem dúvida, uma contribuição na formação dos alunos, mediante a realização de diversas atividades que não se fazem constantemente no dia a dia escolar dos estudantes. Essa experiência foi positiva, dado os resultados obtidos com avaliações de desempenho individual e coletivo.

Esse trabalho pode ser utilizado como uma alternativa para o ensino de biologia, no entanto, não como uma receita pronta e acabada, pois, assim como diversos fatores interferiram nesta experiência, assim pode também ocorrer e, portanto, o professor deve sempre buscar melhorar ou adequar a sua turma.

Mesmo sendo essa a realidade da maioria das escolas brasileiras (alunos desinteressados e/ou focados na realização de outras atividades para a obtenção de "notas pendentes"), devemos continuar nossa caminhada enquanto professores, sempre visando uma educação de qualidade e buscando cada vez mais alternativas diferenciadas para o ensino de biologia.

Recebido em: 06/03/2019, Reapresentado em: 13/09/2019 e Aprovado em:29/09/2019

\section{Referências}

ANDRADE, Mariana Aparecida Bologna Soares de; CAMPOS, Luciana Maria Lunardi. Possibilidades e Limites da Prática da Aprendizagem Baseadas em Problemas (PBL) no Ensino Médio. Enseñanza de Las Ciencias, Espanha, n. 7, 2005. Número extra. 
BARBOSA, Paulina Maria Maia; ALONSO, Rodrigo Soares; VIANA, Flávia Elizabeth de Castro. Aprendendo ecologia através de cartilhas. Anais do $7^{\circ}$ Encontro de Extensão da Universidade Federal de Minas Gerais. Belo Horizonte, 2004. Disponível em: https://www.ufmg.br/congrext/Meio/Meio36. pdf. Acesso em: 08 set. 2019

BORDENAVE,J.D.;PEREIRA, A. M. Estratégias de ensino-aprendizagem. 1.ed. Petrópolis, RJ:Vozes, 2002.

BROCK, Colin.; SCHWARTZMAN, Simon. Os desafios da educação no Brasil. 1. ed. Rio de Janeiro: Nova Fronteira, 2005.

FERNANDES,HylioLagariá.Umnaturalistana sala deaula.Ciência\& Ensino.Campinas, v.5, p.10-12, 1998.

JACOBI, Pedro. Educação Ambiental, Cidadania e sustentabilidade. Cadernos de Pesquisa, São Paulo: FCC, n. 118, p. 189-205, março/ 2003

KOBASHIGAWA, et al (2008). Estação ciência: formação de educadores para o ensino de ciências nas séries iniciais do ensino fundamental. In: IV Seminário Nacional ABC na Educação Científica. São Paulo, p. 212-217. Disponível em: <http://www. cienciamao.usp.br/dados/smm/_ estacaocienciaformacaodeeducadoresparaoensinodecienciasn asseriesiniciaisdoensinofundamental. trabalho.pdf >. Acesso em: 30/07/2019.

KLEIN, Ruben; RIBEIRO, Sérgio Costa. O censo educacional e o modelo de fluxo: o problema da repetência. Revista Brasileira de Estatística, Rio de janeiro, v. 52, n. 197-198, p. 5-45, jan./dez. 1991.

LIMA, Donizete Franco. A importância da sequência didática como metodologia no ensino da disciplina de física moderna no Ensino Médio. Rev. Triang. Uberaba, v.11, n.1 p.151 - 162 Jan./Abr. 2018

LINHARES, Sérgio.; GEWANDSZNAJDER, Fernando. Biologia hoje. 3 ed. São Paulo: Ática, 2008.

MORIN, Edgar. Introdução ao pensamento complexo. 5.ed. Porto Alegre: Sulina, 2015.

MOREIRA, Marco Antônio. Aprendizagem significativa: a teoria e textos complementares. 1. ed. Livraria da física: Porto Alegre, 2011.

MOREIRA, Ana Elisa da Costa. Relações entre as estratégias de ensino do professor, com as estratégias de aprendizagem e a motivação para aprender de alunos do ensino fundamental 1. 2014. 120f.

Dissertação - Universidade Estadual de Londrina, Centro de Educação, Comunicação e Artes, Londrina, Paraná.

PEREIRA, Helenadja Mota Rios; BAPTISTA, (2008). Geilsa Costa Santos. Uma reflexão acerca do Estágio Supervisionado na formação dos professores de Ciências Biológicas, In: VII ENPEC, Florianópolis, Santa Catarina Disponível em: http://www.posgrad.fae.ufmg.br/posgrad/viienpec/pdfs/948.pdf. Acesso em: 05 set 2019.

SILVA Miriam de Castro. Ensino de ecologia: dificuldades encontradas e uma proposta de trabalho para professores dos ensinos fundamental e médio de João Pessoa. 63f. Trabalho de Conclusão de Curso (TCC) - Centro de Ciências Exatas e da Natureza, Universidade Federal da Paraíba.

NICOLA, Jéssica Anese; PANIZ, Catiane Mazocco. A importância da utilização de diferentes recursos didáticos no ensino de biologia. Infor, Inov. Form., Rev. NEaD-Unesp: São Paulo, v. 2, n. 1, p.355-381, 2016.

SILVA, Jorge Antônio Peixoto. O uso de dinâmicas de grupo em sala de aula. Um instrumento de aprendizagem experiencial esquecido ou ainda incompreendido? Saber Científico, Porto Velho. v. 1, n. 2, p. 82- 99, jul/dez. 2008.

SILVA, Cirlande Cabral da; MACIEL-CABRAL, Hiléia Monteiro; NERY, Ursula Rayandra Soares. "Classificando os artrópodes": alternativa para o ensino dos artrópodes para alunos do Ensino 
Fundamental. Revista Eletrônica Científica Ensino Interdisciplinar - RECEI. Mossoró, v.3, n.9, p. 493 506, 2017

TAPIA, Jesus Alonso; FITA, Enrique Caturla. Contexto, motivação e aprendizagem. In: Tapia, Jesus Alonso; FITA, Enrique Caturla (Org.). A motivação em sala de aula: o que é, como se faz. São Paulo: Loyola, 2004. p. 12-61.

UCHOA, Pablo do Nascimento. A importância do estágio supervisionado para a formação docente: um relato de experiência. Revista Didática Sistêmica, Rio Grande do Sul, v.17 n.2, p.43-57, 2015.

ZABALA, Antoni. A prática educativa: como ensinar. 2. ed. Porto Alegre: Artmed, 1998. 